\title{
Wavelet transform as a postprocessing diagnostic tool for fault identifications of high-voltage direct current transmission system
}

\author{
P. Sanjeevikumar ${ }^{a \star}$, and Frede Blaabjerg ${ }^{b}$ \\ ${ }^{a}$ Research and Development, Ohm Technologies, Chennai 600 122, India, ${ }^{b}$ Department of Energy \\ Technology, Center of Reliable Power Electronics (CORPE), Aalborg University, Pontoppidanstraede 101, \\ 9220 Aalborg, Denmark \\ *sanjeevi12@yahoo.co.in
}

\begin{abstract}
This short communication focuses on exploiting the inherent advantages of discrete wavelet transformation (DWT) as a diagnostic tool for post-processing and for identifying the faults that occur in the standard high-voltage direct-current (HVDC) transmission network. In particular, a set of investigations are developed and examined for single-line-to-ground fault on the generation and on the load side converter, and DC-link fault. For this purpose, a standard 12-pulse line-commutated converter (LCC)-HVDC transmission network along with the DWT algorithm is numerically modeled in the MATLAB/PLECS simulation software. Furthermore, in this paper, a set of designed faulty conditions are predicted using the output of DWT and the results of numerical simulation are presented. Results are in good agreement with expectations to prove that DWT is an effective tool for fault diagnostics.
\end{abstract}

Citation: Sanjeevikumar P, and Blaabjerg F. 2016. Wavelet transform as a postprocessing diagnostic tool for fault identifications of high-voltage direct current transmission system. FACETS 1: 17-26. doi: 10.1 I 39/facets-20 I5-0005

Editor: M. Zahangir Kabir

Received: November 12, 2015

Accepted: January 27, 2016

Published: April 12, 2016

Copyright: (C) 2016 Sanjeevikumar and Blaabjerg. This work is licensed under a Creative Commons Attribution 4.0 International License (CC BY 4.0), which permits unrestricted use, distribution, and reproduction in any medium, provided the original author(s) and source are credited.

Competing interests: PS is currently serving as a Subject Editor for FACETS, but was not involved in review or editorial decisions regarding this manuscript.

Published by: Canadian Science Publishing line-commutated converter, high-voltage direct current

\section{Introduction}

In recent years, a 12-pulse voltage-source converter based on high-voltage direct current (HVDC) transmission network has been widely implemented in real time, because of its outstanding advantages, such as economical efficiency and flexibility. Moreover, HVDC transmission systems that utilize the line-commutated converter (LCC) are successful and have been running for many years (Wang and Sa-Nguyen et al. 2014; Sanjeevikumar et al. 2014). However, on the point of safety, the operation of HVDC systems is essential for both monitoring and better protection. Many research articles have addressed various fault diagnostic postprocessing tools including artificial neural networks, fuzzy control, and other intelligent systems (Nanayakkara 2011, 2012; Mohagheghi et al. 2009). However, under high-power transmission conditions or produced complex strategies, they do not effectively find the fault that has actually occurred. Discrete wavelet transformation (DWT) has found wider applications recently for controlling the AC/DC drives and motors with major benefits and is discussed in detail by Saleh (2013), Hui et al. (2015), Febin Daya et al. (2013a, 2013b, 2015, 2016), and Sanjeevikumar et al. (2015a, 2015b, 2015c). Furthermore, wavelet transforms are applied in the field of HVDC transmission for diagnosis of fault location, analysis, and DC-link failure, but 
a systematic and comprehensive investigation of types of fault identification has not been presented (De Kerf et al. 2011; Yeap and Ukil 2014; de Andrade and Ponce de Leao 2014) and moreover that is not robust to adaptations. DWT is the fast processing algorithm and its inherent capabilities are exploited as a fault diagnostic tool in this paper. A set of three drastic faulty conditions are developed for a 12-pulse LCC-HVDC transmission system as a preliminary investigation to verify the proposal-specifically, single-line-to-ground, on generation and on load end converters, and DC-link faults. The complete AC power system is numerically developed in the MATLAB/PLECS simulation software. The observed results presented in this paper show that DWT accurately predicts the types of developed fault conditions under all conditions, as expected.

\section{Discrete wavelet transform for a 12-pulse LCC-HVDC power system}

Figure 1 shows the schematic circuit of the standard 12-pulse LCC-HVDC transmission system in practice. The well-known synchronous reference frame regulation scheme is employed to control the 12-pulse rectifier and 12-pulse inverter units to perform effectively in the available power transfer from generation to the load center (Sanjeevikumar et al. 2014). A set of three fault conditions are designed as a preliminary task to examine the most common and drastic issues in transmission networks-single-line-to-ground, on generation and on the load side converters, and most important DC-link faults. Furthermore, the research work is kept under study for investigation of types of fault identification and its detailed analysis as near future implementations.

In this analysis, the DWT plays the role of identifying about the set of faults under test and confirms the type of occurrences in the complete system. The input parameter is chosen as power, as it includes the characteristic variation in voltages and currents and adheres to be a simplified solution. The instantaneous power is calculated and fed as input to DWT, which begins processing when a discrete signal $x[n]$ of length $N$ is transmitted. DWT can easily distinguish between the instantaneous power into high-pass signal resulting in an impulse response $h[n]$ and that into a low-pass signal resulting in an impulse $g[n]$, mathematically expressed as follows (Saleh 2013; Hui et al. 2015; Febin Daya et al. 2013a, 2013b, 2015, 2016; Sanjeevikumar et al. 2015a, 2015b, 2015c; Mallat 1989):

$$
d^{1}[n]=\sum_{k=0}^{N-1} x[k] h[n-k] ; a^{1}[n]=\sum_{k=0}^{N-1} x[k] g[n-k]
$$

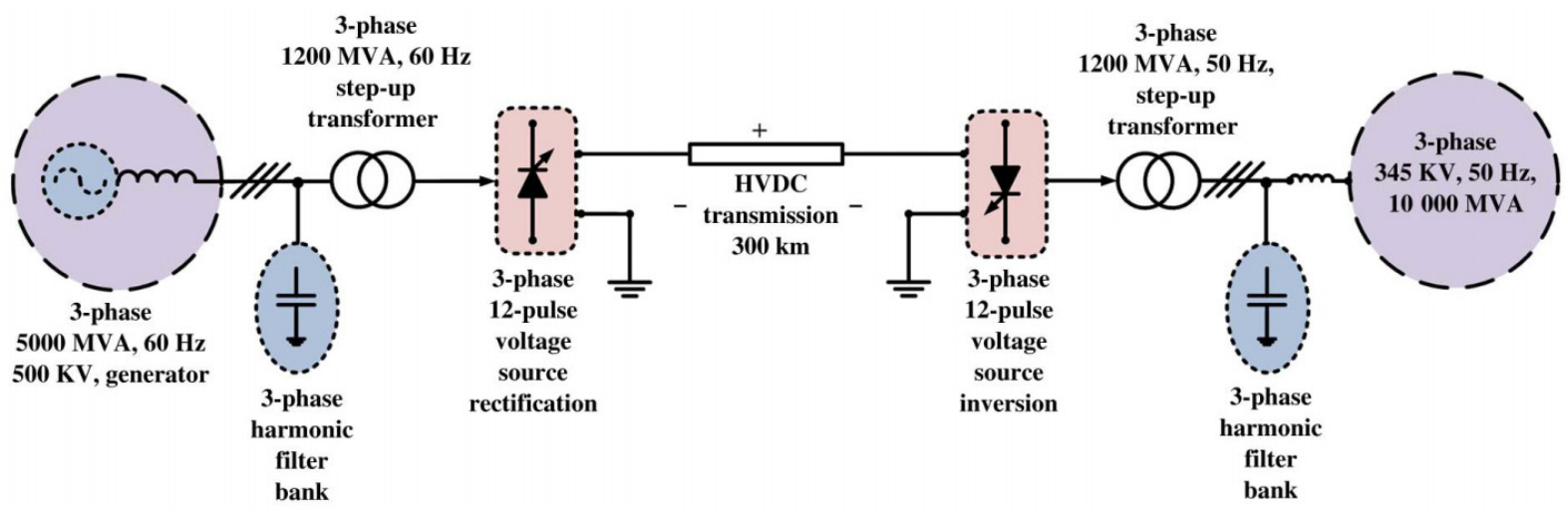

Fig. 1. Schematic circuit of the standard 12-pulse LCC-HVDC transmission network under postprocessing for the fault identification test bench. 
where $d^{1}[n]$ and $a^{1}[n]$ are the outputs of the high- and low-pass filters, respectively. After this processing, again the output from the low-pass filter is down-sampled by two and passed through a lowand a high-pass filter, which resembles the ones in the first level, written as follows (second level of decomposition):

$$
d^{2}[n]=\sum_{k=0}^{N / 2-1} a^{1}[k] h[n-k] ; a^{2}[n]=\sum_{k=0}^{N / 2-1} a^{1}[k] g[n-k]
$$

To be noted, several types of wavelet filters are available and have been investigated, but the minimum description length (MDL) is chosen as the best criterion and is mathematically represented as follows (Febin Daya et al. 2013a, 2013b, 2015, 2016; Sanjeevikumar et al. 2015a, 2015b, 2015c; Mallat 1989):

$$
\operatorname{MDL}(k, n)=\min \left\{\frac{3}{2} k \log N+\frac{N}{2} \log \left\|\tilde{\alpha}_{n}-\alpha_{n}^{(k)}\right\|^{2}\right\}, \quad 0<k<N ; 1 \leq n \leq M
$$

where $\tilde{\alpha}_{n}=W_{n} f$ denotes a vector of the wavelet transformed coefficients of the signal $f$ using wavelet filters $(n) \cdot \alpha_{n}^{(k)}=\varnothing^{K} \tilde{\alpha}_{n}=\varnothing^{K}\left(W_{n} f\right)$ denotes a vector that contains $k$ nonzero elements. The threshold parameter $\varnothing^{K}$ keeps $k$ number of the largest elements of the vector $\tilde{\alpha}_{n}$ constant and sets all other elements to zero. $N$ and $M$ denote the length of the signal and the number of wavelet filters, respectively. The entropy $H(x)$ of a signal $x[n]$ of length $N$ is defined by

$$
H(x)=-\sum_{n=0}^{N-1}|x(n)|^{2} \log |x(n)|^{2}
$$

For determining the optimal levels of decomposition, the entropy is evaluated at each level. For a new level $j$, the entropy works as the following constraint:

$$
H(x)_{j} \geq H(x)_{j-1}
$$

A two-level decomposition method is sufficient for the effective representation of HVDC transmission system identifying the type of fault. The components (low- and high-frequency components) were scaled by their respective gains and then added together to generate the control signal $u$ :

$$
u=k_{d^{1}} e_{d^{1}}+k_{d^{2}} e_{d^{2}}+\cdots+k_{d^{N}} e_{d^{N}}+k_{a^{N}} e_{a^{N}}
$$

where gains $k_{d^{1}}, k_{d^{2}}, \ldots, k_{d^{N}}$ are used to tune the high- and medium-frequency components of the fault (instantaneous power) signal $\left(e_{d^{1}}, e_{d^{2}}, \ldots, e_{d^{N}}\right)$. Gain $k_{a^{N}}$ is used to tune the lowfrequency components of the fault signal $\left(e_{a}^{N}\right)$ under test and $N$ is the number of decomposition levels.

\section{Numerical simulation results and discussion}

For numerical verifications the following parameters are considered and fault occurrences are numerically designed with time intervals as described in Table 1 . The DC transmission line length equals $300 \mathrm{~km}$, and the AC generator was rated at $5000 \mathrm{MVA}$ at $60 \mathrm{~Hz}$, and load end utility of $500 \mathrm{kV}$. The transformers are rated, the rectifier and inverter ends at $1200 \mathrm{MVA}$, with grid $345 \mathrm{kV}, 50 \mathrm{~Hz}$, 10,000 MVA, and power transmission capacity of $1000 \mathrm{MW}$.

In the first investigation test, Fig. 2 shows the simulation response when the 12-pulse LCC-HVDC transmission system is subjected to healthy and single-line-to-ground fault on the generator side by DWT diagnostic tool behavior. Figure $2 a-d$ depict the three-phase generated voltage, generated 
Table 1. Designed criterion for the set of faults.

Type of fault

Fault time (s)

SLG fault (generation end)

$1.60-1.68$

DC-link (HVDC transmission) fault

$5.44-5.52$

SLG fault (load end)

$6.72-6.80$

SLG $=$ single-line-to-ground .

currents, DC-link voltage, and DC-link current, respectively. From the results it is clear that healthy condition exists until the time interval $1.6 \mathrm{~s}$, where the designed fault occurs in the transmission system, eventually leading voltages and currents to behave abruptly above the set ratings until $1.7 \mathrm{~s}$, where again it returns back to healthy conditions as designed for investigation. Figure $2 e$ illustrates the behavior response of fault identification by DWT; it is clearly observed until the healthy conditions output reaches a constant amplitude of 1.7, for all co-efficients of two-level decomposition according to eq. (6). Once, the designed fault occurs at $1.6 \mathrm{~s}$, the DWT output value increases and reaches the peak amplitude of 6 and the contour area widens as expected.

From the amplitude of peak and contour areas, it could be easily distinguished that the fault that occurred is a single-line-to-ground fault on the generator side. Furthermore, DWT returns back to its initial values once the fault is cleared at $1.7 \mathrm{~s}$ (eq. 6), and the contour area also reduces as it appears in healthy conditions. Hence, by DWT spectrum behavior, the healthy and faulty conditions are clearly distinguishable when the system is subjected to the disturbance.

The second investigation test is focused on single-line-to-ground fault identification by DWT on the load end. Figure 3 describes the simulation response, as a 12-pulse LCC-HVDC transmission system subjected to healthy and single-line-to-ground fault on the load side, and DWT diagnostic tool behavior. Figure $3 a-d$ depict the three-phase generated voltage, generated currents, DC-link voltage, and DC-link current, respectively. It was clear from the results that healthy conditions exist until the time $6.72 \mathrm{~s}$, where the designed fault occurs in the transmission system, eventually leading the voltages and currents to behave abruptly as predicted above the set ratings until the time of $6.8 \mathrm{~s}$, where again it returns back to healthy conditions as designed for investigation. Behavior of fault identification by DWT is described in Fig. $3 e$; it is notable until healthy conditions output reaches a constant amplitude of 1.7, all co-efficient of two-level decomposition according to eq. (6). Once, the fault occurs at $6.72 \mathrm{~s}$, the DWT output value increases and reaches the peak of 5.8 in amplitude and the contour area widens as expected.

Furthermore, the contour area generated by DWT outputs is not similar to the first investigation test and it is clearly distinguishable. Hence, the amplitude of peak and contour areas shows that the fault occurred is single-line-to-ground fault on load end. DWT returns back to its initial values once the fault is cleared at $6.8 \mathrm{~s} \mathrm{(eq.} \mathrm{6)} \mathrm{and} \mathrm{the} \mathrm{contour} \mathrm{area} \mathrm{also} \mathrm{reduces} \mathrm{as} \mathrm{it} \mathrm{appears} \mathrm{in} \mathrm{healthy} \mathrm{conditions.}$ Hence, again by DWT spectrum behavior, the healthy and faulty conditions are clearly predictable when the system subjected to the disturbance.

In the third investigation test, Fig. 4 describes the simulation response, as a 12-pulse LCC-HVDC transmission system subjected to healthy and DC-link fault, and DWT diagnostic tool behavior. Figure $4 a-d$ depict the three-phase generated voltage, generated currents, DC-link voltage, and DC-link current, respectively. It is noticed from the results that healthy conditions exist until the time interval $5.44 \mathrm{~s}$, where the designed fault occurs in the transmission system, eventually leading the voltages and currents to behave abruptly as predicted above the set ratings until 5.52 s. Figure $4 e$ elaborates 

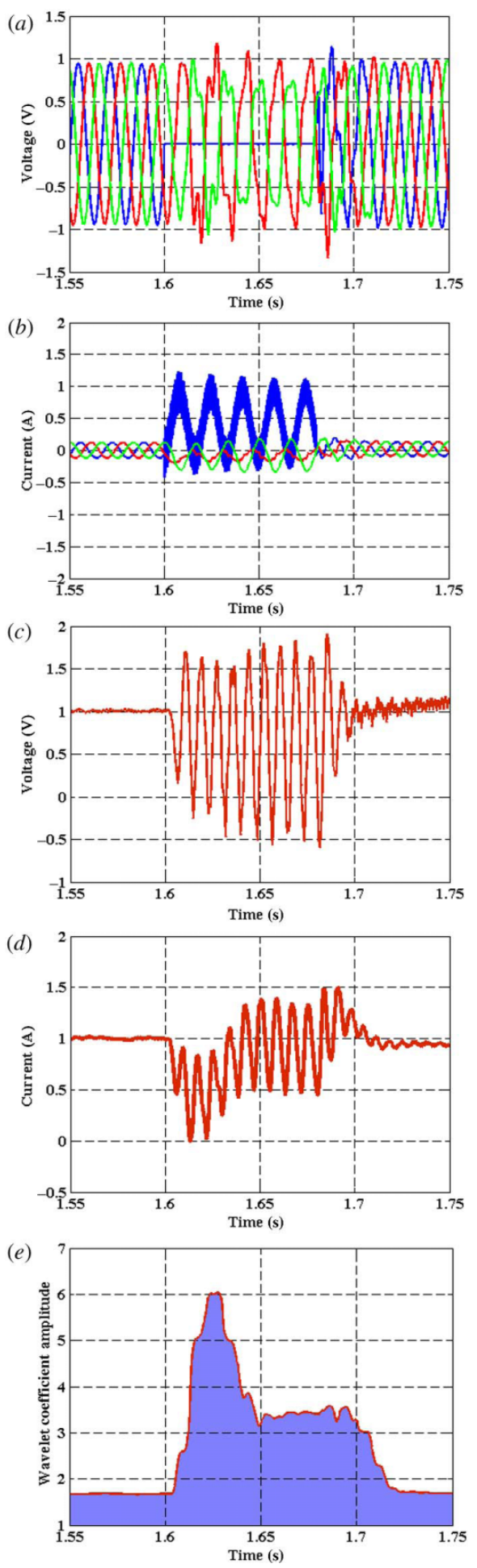

(c)

$(d)$
Fig. 2. Numerical simulation response of the 12-pulse LCC-HVDC transmission system subjected to test includes healthy and generator side single-lineto-ground fault conditions by the DWT diagnostic tool. (a) Three-phase line-to-line voltage measured on the generator side. (b) Three-phase line current measured on the generator side. (c) DC-link measured voltage. (d) DC-link measured current. (e) Discrete wavelet transform response. 


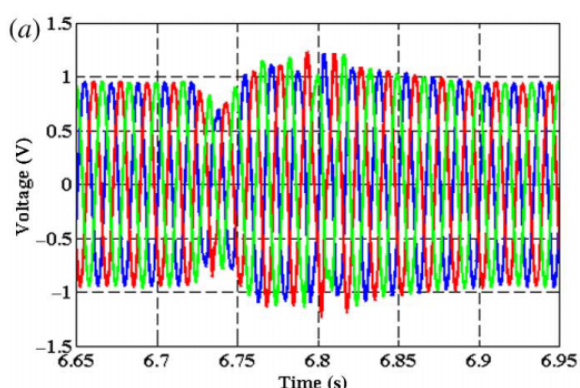

(b)
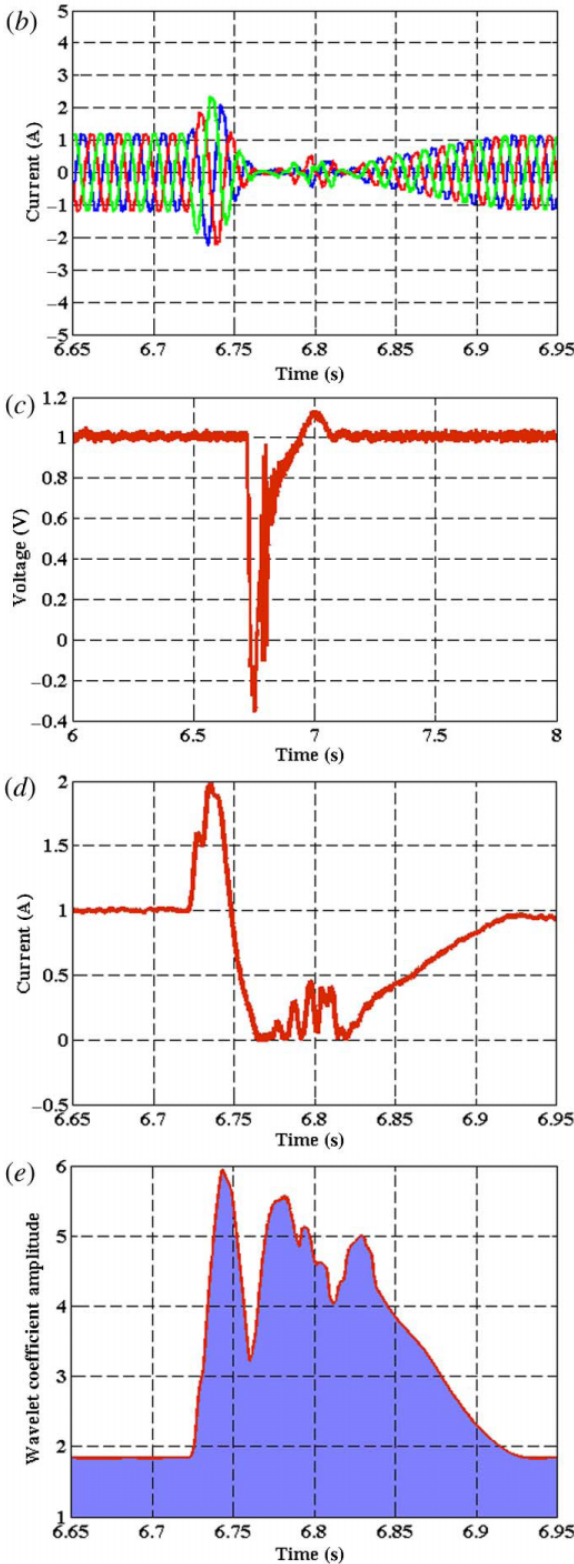

Fig. 3. Numerical simulation response of the 12 pulse LCC-HVDC transmission system subjected to test includes healthy and load inverter side singleline-to-ground fault conditions by the DWT diagnostic tool. (a) Three-phase line-to-line voltage measured on the generator side. (b) Three-phase line current measured on the generator side. (c) DC-link measured voltage. $(d)$ DC-link measured current. (e) Discrete wavelet transform response. 

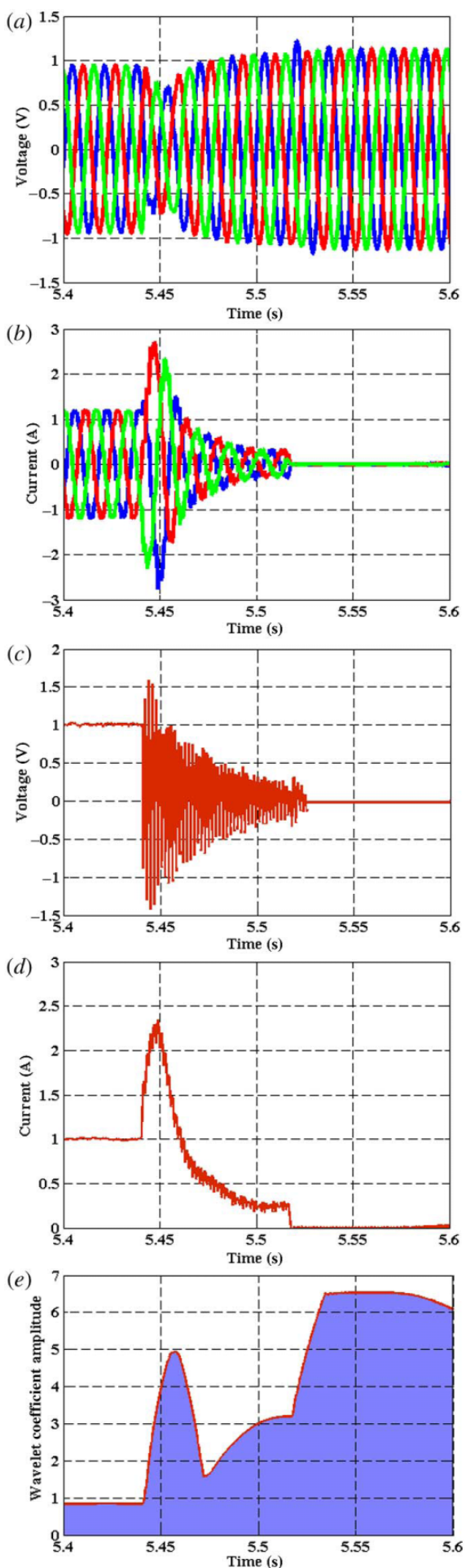

Fig. 4. Numerical simulation response of the 12-pulse LCC-HVDC transmission system under test subjected to healthy and DC-link fault conditions by the DWT diagnostic tool. (a) Three-phase line-to-line voltage measured on the generator side. (b) Three-phase line current measured on the generator side. (c) DC-link measured voltage. (d) DC-link measured current. (e) Discrete wavelet transform response. 
the behavior of fault identification by DWT; it is observed until healthy conditions output reaches a constant amplitude of 1.7, all co-efficient of two-level decomposition according to eq. (6). Once, the fault occurs at $5.44 \mathrm{~s}$, the DWT output value increases and reaches the peak of 5.8 in amplitude and the contour area widens as expected. To be noted, that the contour area generated by DWT outputs is not similar to the first and second investigation tests and it is clearly distinguishable.

Furthermore, it should be noted that once the DC fault occurs at time interval $5.52 \mathrm{~s}$, drastic failure occurs and the complete system needs to be protected. So, the generator side is open-circuited from DC link similar to the load side; therefore, the AC generator, rectifier, and inverter on the load side are protected. However, voltage generated after the time $5.52 \mathrm{~s}$ is purely open-circuited (Fig. $4 a$ ), whereas three-phase current on the generator side, DC-link voltage, and DC-link current are null, which confirms the protection and open-circuited conditions. Hence, the amplitude of peak and contour areas shown by DWT confirm that the fault occurred is DC-link fault on the load end and also the open-circuit protection state. It is concluded from these three preliminary investigation tests that DWT is capable of predicting a diagnostic tool when the HVDC transmission system suffers with different faults.

\section{Conclusion}

This short communication exploited the capabilities of DWT as a postprocessing tool to identify the fault in a 12-pulse standard LCC-HVDC transmission system. A set of faulty conditions are designed and numerically implemented using the simulation software (MATLAB/PLECS). A set of observed results are presented and show good agreement with expectation under healthy and different fault conditions. Furthermore, the challenging task related to other types of fault and fault occurrences during transient conditions and the effect of leakage reactance on faults with sag/swell need to be investigated and will be addressed in future articles. Moreover, the DWT application can be extended to other transmission system types such as FACTS devices (STATCOM, SSSC, and UPQC) and active filters.

\section{Author contributions}

Conceived and designed the study: PS, FB. Performed the experiments/collected the data: PS, FB. Analyzed and interpreted the data: PS, FB. Drafted or revised the manuscript: PS, FB.

\section{Data accessibility statement}

All relevant data are within the paper.

\section{References}

de Andrade L, and Ponce de Leao MT. 2014. Fault location for transmission lines using wavelet. IEEE Transaction on Latin America, 12(6): 1043-1048. doi:10.1109/TLA.2014.6893998.

De Kerf K, Srivastava K, Reza M, and Bekaert D. 2011. Wavelet-based protection strategy for DC faults in multi-terminal VSC HVDC systems. IET Journal of Generation, Transmission and Distribution,

5(4): 496-503. doi:10.1049/iet-gtd.2010.0587.

Febin Daya JL, Sanjeevikumar P, Blaabjerg F, Wheeler PW, and Ojo JO. 2015. Implementation of wavelet based robust differential control for electric vehicle application. IEEE Transaction on Power Electronics, 30(12): 6510-6513. doi:10.1109/TPEL.2015.2440297. 
Febin Daya JL, Sanjeevikumar P, Blaabjerg F, Wheeler PW, Ojo JO, and Ahmet HE. 2016. Analysis of wavelet controller for robustness in electronic differential of electric vehicles-An investigation and numerical implementation. Journal of Electric Power Components and Systems. doi:10.1080/ 15325008.2015.1131771.

Febin Daya JL, Sanjeevikumar P, Subbiah V, and Iqbal A. 2013a. A novel wavelet-fuzzy based indirect field oriented control of induction drives. Journal of Power Electronic, 13(4): 656-668. doi:10.6113/JPE.2013.13.4.656.

Febin Daya JL, Subbiah V, and Sanjeevikumar P. 2013b. Robust speed control of an induction motor drive using wavelet-fuzzy based self-tuning multi-resolution controller. International Journal of Computational Intelligence System, 6(4): 724-738. doi:10.1080/18756891.2013.803741.

Hui L, Poh Chiang L, and Blaabjerg F. 2015. Sub-module short circuit fault diagnosis in modular multilevel converter based on wavelet transform and adaptive neuro fuzzy inference system. Journal of Electric Power Components and Systems, 43(8): 1080-1088. doi:10.1080/15325008.2015.1022668.

Mallat SG. 1989. A theory for multi-resolution signal decomposition: The wavelet representation. IEEE Transactions on Pattern Analysis and Machine Intelligence, 11(7): 674-693. doi:10.1109/ 34.192463.

Mohagheghi S, Harley RG, Habetler TG, and Divan D. 2009. Condition monitoring of power electronic circuits using artificial neural networks. IEEE Transaction on Power Electronics, 24(10): 2363-2367. doi:10.1109/TPEL.2009.2017806.

Nanayakkara OMKK. 2011. Location of DC line faults in conventional HVDC systems with segments of cables and overhead lines using terminal measurements. IEEE Transaction on Power Delivery, 27(1): 279-288. doi:10.1109/TPWRD.2011.2174067.

Nanayakkara OMKK. 2012. Traveling-wave-based line fault location in star-connected multiterminal HVDC systems. IEEE Transaction on Power Delivery, 27(4): 2286-2294. doi:10.1109/ TPWRD.2012.2202405.

Saleh SA. 2013. The implementation and performance evaluation of $3 \Phi$ VS wavelet modulated AC-DC converters. IEEE Transaction on Power Electronics, 28(3): 1096-1106. doi:10.1109/ TPEL.2012.2205945.

Sanjeevikumar P, Febin Daya JL, Blaabjerg F, Mir-Nasiri N, and Ahmet HE. 2015a. Numerical implementation of wavelet and fuzzy transform IFOC for three-phase induction motor. The Engineering Science And Technology: An International Journal, 19(1): 96-100. doi:10.1016/ j.jestch.2015.07.002.

Sanjeevikumar P, Febin Daya JL, Blaabjerg F, Wheeler PW, Szcześniak P, Oleschuk V, and Ahmet HE. 2015b. Wavelet-fuzzy speed indirect field oriented controller for three-phase AC motor drive-investigation and implementation. Engineering Science and Technology: An International Journal. doi:10.1016/j.jestch.2015.11.007.

Sanjeevikumar P, Febin Daya JL, Wheeler PW, Blaabjerg F, Fedák V, and Ojo JO. $2015 c$. Wavelet transform with fuzzy tuning based indirect field oriented speed control of three-phase induction motor drive. In Proceedings of the 18th IEEE International Conference on Electrical Drives and Power Electronics, IEEE-EDPE'15, Tatranska Lomnica, Slovakia, 21-23 September 2015, pp. 111-116. doi:10.1109/EDPE.2015.7325279. 
Sanjeevikumar P, Paily B, Basu M, and Conlon M. 2014. Classification of fault analysis of HVDC systems using artificial neural network. In Proceedings of the 49th IEEE Universities Power Engineering Conference, IEEE-UPEC’14, Cluj-Napoca, Romania, 2-5 September 2014, pp. 1-5. doi:10.1109/UPEC.2014.6934775.

Wang L, and Sa-Nguyen TM. 2014. Stability enhancement of large-scale integration of wind, solar, and marine-current power generation fed to an SG-based power system through an LCC-HVDC link. IEEE Transaction on Sustainable Energy, 5(1): 160-170. doi:10.1109/TSTE.2013.2275939.

Yeap YM, and Ukil A. 2014. Wavelet based fault analysis in HVDC system. In Proceedings of the 40th Annual Conference of IEEE Industiral Electronics Society, IECON'14, Dallax, TX, USA, 29 October-1 November 2014, pp. 2472-2478. doi:10.1109/IECON.2014.7048852. 